\title{
A física das oscilações mecânicas em instrumentos musicais: Exemplo do berimbau
}

(The Physics of mechanical oscillations in musical instruments: Example of Berimbau)

\author{
Alejandra Kandus ${ }^{1}$, Friedrich Wolfgang Gutmann² e Caio Mário Castro de Castilho ${ }^{3}$ \\ ${ }^{1}$ Laboratório de Astrofísica Teórica e Observacional, Departamento de Ciências Exatas e Tecnológicas, \\ Universidade Estadual de Santa Cruz, Ilhéus, Bahia, Brasil. \\ Instituto de Física, Universidade Federal da Bahia, Salvador, Ba, Brasil \\ Grupo de Física de Superfícies e Materiais, Instituto de Física, Universidade Federal da Bahia, Salvador, Ba, Brasil \\ Recebido em 14/12/2005; Revisado em 6/6/2006; Aceito em 13/7/2006
}

\begin{abstract}
Neste trabalho apresentamos uma breve discussão sobre a propagação de ondas mecânicas em meios elásticos, em particular ao longo de cordas e no ar. Os princípios básicos da propagação de ondas são ilustrados com o funcionamento de instrumentos musicais, tomando como exemplo um instrumento típico do estado da Bahia e conhecido por todos os brasileiros, o berimbau.

Palavras-chave: oscilações mecânicas, instrumentos musicais, berimbau.
\end{abstract}

In this work it is discussed the wave propagation in an elastic medium, particularly along strings and the air. The basic principles of the wave propagation are presented, taking as an example case a typical instrument from the state of Bahia, well known by all Brazilians, the berimbau.

Keywords: mechanical oscillations, musical instruments, berimbau.

\section{Introdução}

Este instrumento musical, que é atualmente componente fundamental da prática da capoeira, é formado por um galho roliço onde estica-se um arame formando um arco que tem, em uma de suas extremidades, uma cabaça. Esta cabaça faz o papel de "caixa de ressonância" para as vibrações produzidas no arame. O comportamento do arame é assim o mesmo de uma corda fixa nos dois extremos. Quando fazemos o arame vibrar puxando-o ou percutindo-o, observamos que a vibração desaparece com certa rapidez. Isso é devido à ação das forças dissipativas: o atrito elástico no interior da corda e também as forças que colocam ligeiramente em movimento vibratório o que a estiver prendendo em seus pontos fixos. Apenas parte dessa perda de energia é realmente convertida em energia ondulatória sonora. Uma corda que vibra, fixa em extremos rígidos, produz apenas um som fraco: a maior parte da energia de vibração desaparece na forma de energia de atrito (calor). A conversão em energia ondulatória sonora pode ser melhorada conectando-se ou instalando-se a corda junto a uma caixa de propriedades elásticas especiais, chamada de ressoador (a caixa de resonância do piano, ou o corpo do violão, ou a cabaça do berimbau). Nesse

\footnotetext{
${ }^{3}$ E-mail: caio@ufba.br.

caso, permite-se que as extremidades da corda vibrem um pouco. Tão pouco que, em comparação com o resto das vibrações da corda, essas extremidades ainda funcionam tecnicamente como pontos de repouso (nodos), e a energia da corda pode ser gradualmente convertida em energia de vibração da caixa. Devido à superfície da caixa ser geralmente grande, essa energia será então convertida com maior eficiência em energia ondulatória sonora. O som produzido é muito mais intenso que no caso de uma corda instalada rigidamente - mas ele decai mais depressa, por causa da razão consideravelmente maior com que a quantidade disponível de energia da corda é "gasta", na verdade transferida para o ar.

No caso específico do berimbau, a cabaça é fixada ao arco por meio de um fio que passa por dois pequenos furos na base da cabaça, segundo pode-se ver na Fig. 1. Assim, ela pode ser considerada como uma caixa de ressonância com "duas aberturas": uma, a principal, é a boca e a outra corresponde aos dois furinhos mencionados acima. Embora estes furos sejam pequenos, o seu diâmetro é suficientemente grande para considerar que a pressão do ar dentro da cabaça e logo em frente aos furos, é igual à exterior, a pressão atmosférica. Além disso, o fato de que a distância entre os furos é pequena em comparação com as dimensões carateríisticas 
da cabaça, permite a consideração de que temos um único furo.

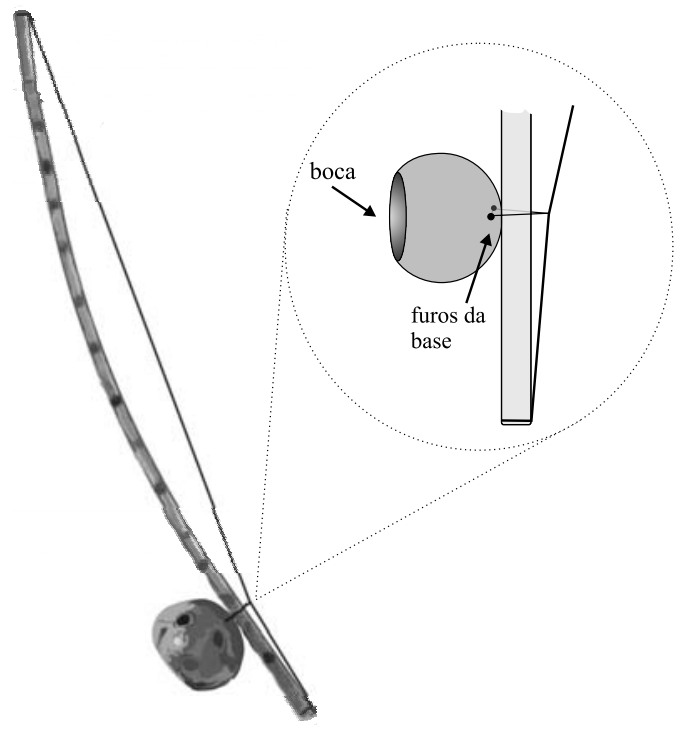

Figura 1 - Esquema representativo de um berimbau. No detalhe podem ser vistos os furos por onde passam um cordão que fixa a cabaça à peça de madeira e ao arame.

Devido ao recém exposto, a cabaça pode ser considerada como semelhante a um cilindro aberto nos dois extremos, quando o berimbau é executado com a cabaç afastada da barriga, ou como um cilindro aberto num extremo (os furinhos) e fechado no outro (a boca) quando a cabaça está apoiada na barriga. Na verdade, a cabaça seria melhor aproximada por uma esfera que por um cilindro. Ocorre que, para um tratamento adequado ao caso da esfera, necessitaríamos de recursos matemáticos mais sofisticados que os adequados aos objetivos deste texto.

Então, para estudar a amplificação ressonante das ondas excitadas no arame do berimbau, vamos considerar um modelo simples, no qual somente uma das dimensões características da cabaça, o seu comprimento, determina os possíveis modos ressonantes. Esta aproximação se torna mais precisa quanto mais alongada for a cabaça.

\section{O som do berimbau}

A discussão a respeito do som produzido em um berimbau requer uma análise a respeito das vibrações numa corda fixa nos extremos - o arame - e sobre as vibrações do ar num recipiente aberto nos dois extremos ou aberto em um e fechado no outro - a cabaça.

\subsection{Um pouco da física das vibrações na corda e na cabaça.}

Consideremos o caso de uma corda tensa, presa nos extremos, representados como os pontos fixos $A$ e $B$ da Fig. 2. Suponhamos que a corda possui um comprimento total $L$ e massa por unidade de comprimento $\mu$ (densidade linear da corda), e que seja mantida esticada por uma certa força $T$, que pode ser variada à vontade. Quando se afina um violão, o apertar/afrouxar das tarraxas resulta em variar esta força. Suponhamos que a corda é dedilhada ou percutida num certo ponto. Dois pulsos ondulatórios elásticos transversais vão se propagar, um para a esquerda e outro para a direita, afastando-se da região de perturbação inicial com uma certa velocidade. É possível mostrar que a velocidade dos pulsos elásticos numa corda depende da tensão aplicada e da densidade segundo

$$
V_{T}=\sqrt{\frac{T}{\mu}} \frac{\mathrm{m}}{\mathrm{s}} .
$$

Vale observar que a velocidade de propagação não depende da intensidade com que percutimos a corda.

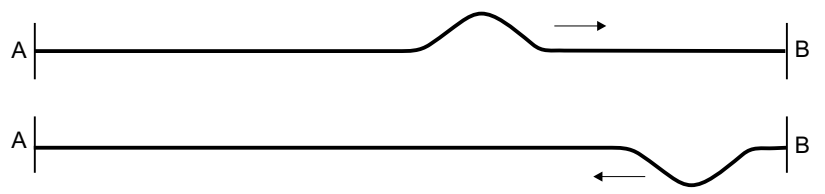

Figura 2 - Um pulso que se desloca para a direita é refletido no ponto de fixação, retornando com a mesma velocidade de propagação, mas invertido. Uma sucessão de pulsos produzidos num mesmo sentido encontrará pulsos invertidos, dando origem a pontos em repouso, denominados nodos. Para uma corda fixa nos dois extremos, dois dos nodos são os próprios extremos.

Consideremos a situação descrita acima, com ondas propagando-se para a frente e para trás ao longo de uma corda. Ondas produzidas numa corda e que são refletidas nos pontos fixos, resultam na formaçāo de uma onda estacionária, ou seja, teremos pontos que não se deslocam em virtude do "cancelamento" dos esforços em sentidos contrários, e pontos que se deslocam oscilantemente, não sendo no entanto possível identificar o sentido de propagação da onda como um todo. Na verdade, pode-se mostrar matematicamente que as ondas estacionárias são a única forma estável possível de vibração numa corda com as extremidades fixas (pontos $A$ e $B$ da Fig. 2) exercendo o papel de nodos. Isto tem uma conseqüência muito importante. Entre todas as formas imagináveis de ondas estacionárias, só são possíveis aquelas cujos nodos incluam os pontos $A$ e $B$. Em outras palavras, são permitidas apenas aquelas ondas estacionárias senoidais que possuam uma distância entre nodos, $\ell$, que "caibam" um número inteiro de vezes entre $A$ e $B$. O caso mais simples corresponde à situação onde os únicos nodos são justamente os extremos, correspondendo assim ao primeiro exemplo da Fig. 3. Neste caso, a distância entre os nodos, $\ell$, corresponde a meio comprimento de onda. O caso seguinte corresponde à situação em que há um nodo adicional, situado a meia distância entre os extremos. Neste caso, $\ell$ é metade do comprimento da corda, ou seja, o comprimento de onda é igual à distância entre os extremos. A Fig. 3 mostra os dois primeiros casos e mais dois, 
dos muitos possíveis. Desta maneira, generalizando, são possíveis de formação ondas estacionárias para as quais o comprimento da corda $L$ é um múltiplo inteiro da distância entre nodos. Esta distância entre nodos sucessivos corresponde a meio comprimento de onda, $\ell_{n}$, portanto sendo válida a relação

$$
\ell_{n}=\frac{\lambda}{2}
$$

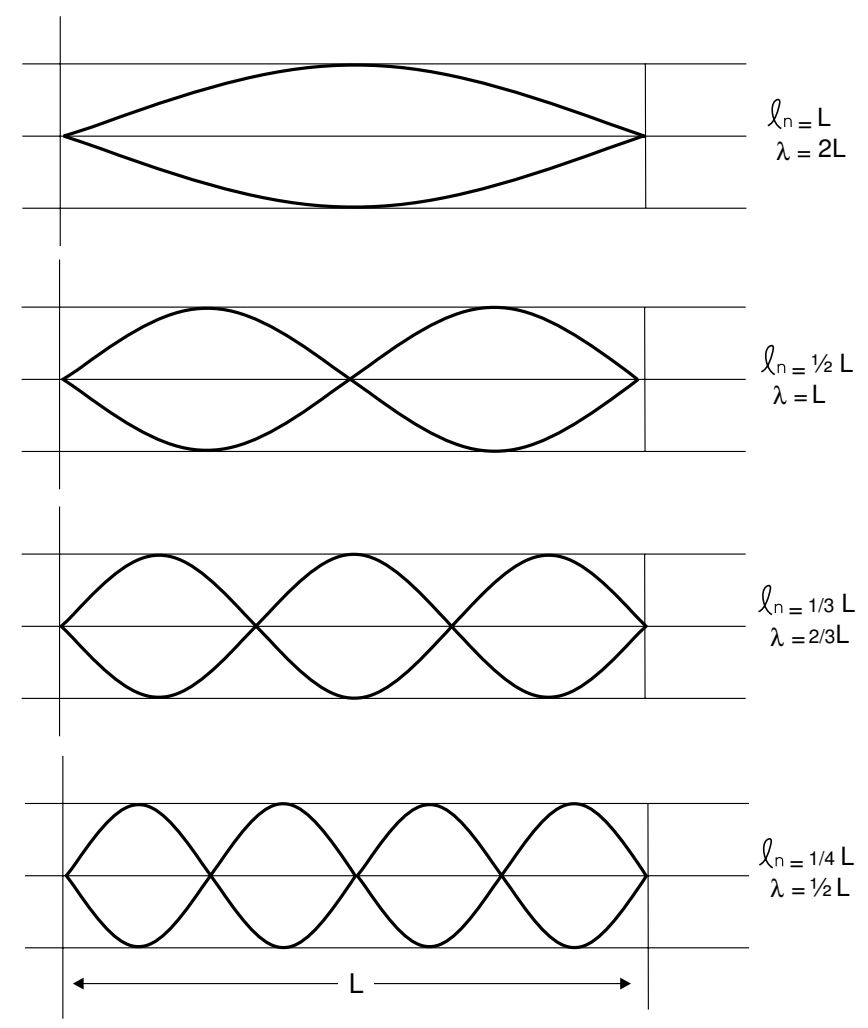

Figura 3 - Figura mostrando os quatro primeiros harmônicos de uma corda fixa nos extremos.

Levando em conta essa relação, obtemos a condição

$$
L=n \ell_{n}=n \frac{\lambda}{2}
$$

onde $n$ é um número natural qualquer, $1,2,3, \ldots$ Isso nos diz que são permitidos apenas os seguintes comprimentos de onda

$$
\lambda_{n}=\frac{2 L}{n}, \quad n=1,2,3, \ldots
$$

A velocidade, $V_{T}$, de uma onda está relacionada com a sua freqüência, $f$, e com o seu comprimento de onda segundo

$$
V_{T}=\lambda f
$$

Assim, usando a relação acima, juntamente com a Eq. (1), teremos:

$$
\lambda=\frac{1}{f} \sqrt{\frac{T}{\mu}} .
$$

Verificamos então que uma corda só pode vibrar com freqüências que são múltiplos de uma freqüência fundamental, ou seja,

$$
f_{n}=\frac{1}{\lambda_{n}} \sqrt{\frac{T}{\mu}}=\frac{n}{2 L} \sqrt{\frac{T}{\mu}}=n f_{1} .
$$

A freqüência mais baixa possível é obtida para $n=1$

$$
f_{1}=\frac{1}{2 L} \sqrt{\frac{T}{\mu}} .
$$

Vale observar na Eq. 7 que todas as outras freqüências possíveis são múltiplos inteiros da freqüência fundamental. Elas são chamadas de "modos" de vibração ou harmônicos superiores de $f_{1}$. Na Fig. 3 são esquematizados os primeiros quatro modos de vibração de uma corda.

\subsection{Ondas estacionárias num cilindro de ar}

Os instrumentos musicais chamados "de vento" consistem basicamente de um cilindro de paredes rígidas onde o ar, no seu interior, é levado a vibrar por algum mecanismo de excitação. Sendo o ar um meio elástico, as ondas que nele se deslocam têm as mesmas propriedades que as das cordas. Isto é, no ar também ocorre o princípio de superposição de ondas e igualmente aparecem os fenômenos de interferência, de batimento e de formação de ondas estacionárias. A diferença entre as ondas dos dois sistemas é que as da corda são transversais e as do ar longitudinais. Nos instrumentos "de vento", como o órgão e a flauta, as ondas estacionárias são excitadas insuflando ar num dos extremos. Os possíveis modos de vibração do ar dependerão do outro extremo do instrumento ser fechado ou aberto. Os tubos de órgão podem ser tanto abertos como fechados e, além disto, ter comprimentos distintos. Na flauta, no entanto, o outro extremo é sempre aberto, neste caso um tubo de comprimento fixo mas com orifícios que, mantidos abertos ou fechados, determinam as distintas notas.

O mesmo fenômeno de ar vibrando acontece numa caixa de ressonância, mas o mecanismo de excitação é outro: as vibrações das paredes da caixa fazem o ar vibrar.

A velocidade de propagação de ondas no ar depende apenas da temperatura $T$ e do peso molecular $M$ do gás no qual elas se deslocam, não dependendo da pressão. A velocidade das ondas no ar, denotada como $c$, varia segundo

$$
c=\sqrt{\frac{\gamma R T}{M}},
$$

onde $\gamma$ é uma constante de proporcionalidade e $R$ é uma constante, chamada de constante universal dos gases ideais. As dimensões de $R$ são tais que o produto $R T$ tem dimensões de energia e portanto $R T / M$ tem 
dimensão de velocidade ao quadrado. Observe-se que, quanto maior a temperatura, maior será $c$. O fato desta velocidade, para um dado gás, depender só de $T$, não deve nos surprender: quanto maior seja $T$ tanto maior será a velocidade associada à energia cinética média das moléculas do gás e portanto maior a velocidade com que "as mensagens", i.e., vibrações, são transmitidas nesse gás.

Numa onda senoidal transversal, como as das cordas, a posição efetiva dos pontos que inicialmente estão sobre uma reta paralela à direção de propagação tem a forma de uma curva como a função seno. Numa onda longitudinal isto não acontece, devido ao fato de que os pontos se deslocam ao longo da mesma direção de propagação da onda, i.e., na mesma reta. O que se observa, neste caso, são aumentos e diminuições alternadas da densidade do meio onde a vibração se propaga, na forma ilustrada na Fig. 4a. A variação de densidade é uma função senoidal que está "desfasada" (neste caso adiantada) em um quarto de comprimento de onda com respeito à da deformação (afastamento da posição de equilíbrio). Observe-se que os locais onde a densidade é a máxima ou a mínima são justamente aqueles que têm deslocamento nulo, já que é ali justamente onde estão os pontos que se aproximam ou se afastam uns dos outros (Fig. 4a). As Figs. $4 b$ e $4 c$ mostram, respectivamente, as variações da posição das partículas e a variação da densidade do gás ao longo do cilindro.

No caso particular de uma onda acústica senoidal num gás, temos que a densidade é proporcional à pressão. A descrição em termos da pressão é preferível à descrição em termos da densidade, já que os deslocamentos são em geral muito pequenos e difíceis de medir na prática. Por outra parte, as variações de pressão são muito mais fáceis de visualizar e de medir, além do que são elas as detectadas pelos nossos ouvidos.

Neste ponto, devemos fazer alguns esclarecimentos [1]: o som é produzido ao criarmos algum tipo de mecanismo que altere a pressão do ar em nossa volta. Na verdade, para a produção do som, é mais importante a velocidade com que a pressão varia (o gradiente de pressão, no "jargão dos físicos") do que o seu valor absoluto. Por essa razão é que um balão cheio de ar não faz praticamente nenhum barulho ao deixarmos o ar sair de dentro dele naturalmente. Por outro lado, se o balão estourar (e o ar sair todo de uma vez), existe uma variação enorme de pressão e um ruído alto é produzido. Podemos então dizer que o som é produzido ao colocarmos uma quantidade (massa) de ar em movimento brusco. É a variação brusca de pressão sobre a massa de ar que causa os diferentes sons, dentre eles os que são combinados para criar a música.

Nas seguintes subseções estudamos as ondas estacionárias que podem vibrar num cilindro aberto nas duas extremidades, e aberto numa e fechado na outra. É importante ressaltar aqui que, sempre, um dos extremos tem que ser aberto, já que é através da aberura que se excita o ar que fica no interior do cilindro.

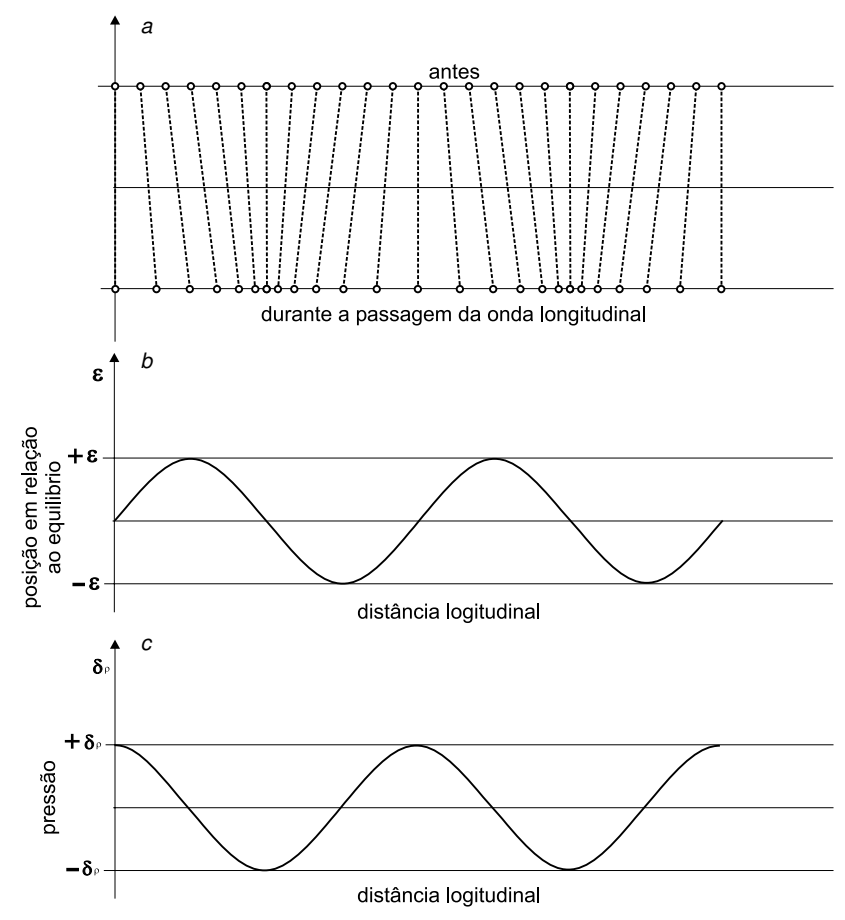

Figura 4 - a. A figura mostra a variação das posições das partículas de um gás numa vibração longitudinal, com as posições de equilibrio indicadas acima e, logo abaixo, as posições com a perturbação. Na figura $b$ mostra-se a variação lateral das posições, e na $c$, a variação da pressão.

\subsubsection{Cilindro de ar aberto nos dois extremos}

Neste caso, em ambos os extremos temos um nodo de pressão. Isto é assim porque o ar dentro do tubo está em contato com o ar exterior, que está a uma pressão fixa, em geral a pressão atmosférica. Desta maneira, as vibrações produzidas no ar que está no interior do cilindro corresponderão a variações de pressão em relação à pressão externa. A amplitude de vibração, pelo contrário, apresenta ventres nesses pontos extremos. Como as moléculas de ar não têm nenhum obstáculo no seu caminho, elas podem se deslocar livremente para dentro e para fora do cilindro, ou seja, vibrar com a máxima amplitude possível. O que acontece com a pressão é que, semelhantemente ao que acontece com o caso da corda, refletido pela Eq. 2, é possível estabelecer uma relação entre a dimensão característica (comprimento) do meio vibrante e os possíveis comprimentos de onda, equivalente ao que ocorre com as vibrações na corda fixa em ambos os extremos. Desta maneira, o comprimento de onda dos possíveis modos de vibração do ar se relacionam com o comprimento do tubo $\ell$, segundo

$$
\lambda_{m}=\frac{2 \ell}{m}, \quad m=1,2,3, \ldots
$$

Assim, a vibração fundamental corresponde ao caso em que o comprimento do cilindro é igual a meio com- 
primento de onda. Na Fig. 5 estão esquematizados alguns dos possíveis modos de vibração do ar num cilindro aberto nos dois extremos.

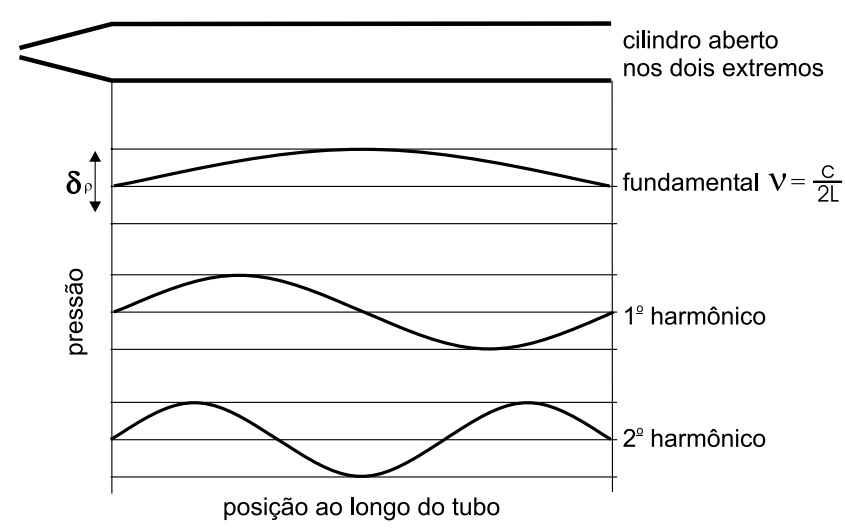

Figura 5 - Na figura temos representados os modos de vibração da pressão correspondentes aos três primeiros harmônicos para o gás no interior de um cilindro aberto nos dois extremos.

\subsubsection{Cilindro aberto num extremo e fechado no outro}

Neste caso, um extremo aberto continuará a existir e, portanto, como no caso anterior, este extremo aberto corresponderá a um nodo de pressão. O extremo fechado passará a ser um ventre de pressão, em razão de que o ar do cilindro está isolado do ar exterior pela parede que o fecha o que, portanto, permite qualquer variação da pressão. Traduzido à linguagem de modos de vibração, isto quer dizer que o comprimento do cilindro tem que ser um número ímpar de vezes a quarta parte do comprimento de onda dos possíveis modos de vibração do ar, como pode ser visto na Fig. 6. Neste caso, então, a relação entre o comprimento de onda dos modos normais e o comprimento do cilindro é

$$
\lambda_{p}=\frac{4 \ell}{2 p+1}, \quad p=0,1,2,3, \ldots
$$

Vale observar que os possíveis valores do denominador são: 1 , para $p$ igual a zero, 3 para $p$ igual a um, 5 para $p$ igual a 2 , i.e., sempre um inteiro ímpar.

Para estudar a amplificação ressonante das ondas excitadas no arame do berimbau, vamos considerar um modelo simples, no qual somente uma das dimensões características da cabaça, o seu comprimento, determina os possíveis modos ressonantes.

Consideremos a situação da cabaça afastada da barriga. Chamemos de $L$ ao comprimento do arame do berimbau e de $\ell$ ao comprimento da cabaça, i.e., sua dimensão entre furos e boca. Desta maneira, serão amplificados apenas os modos excitados no arame cujos comprimentos de onda sejam iguais aos comprimentos de onda possíveis para a cabaça: $\lambda_{n}=\lambda_{m}$, em que o índice $n$ se refere ao fio e o índice $m$ se refere à cabaça. Substituindo nesta igualdade as expressões das Eqs. (4), referente aos possíveis comprimentos de onda no fio, e a Eq. (13), que diz respeito aos possíveis comprimentos de onda na cabaça, obtemos a condição

$$
\frac{2 L}{n}=\frac{2 \ell}{m}
$$

ou seja,

$$
m=\frac{\ell}{L} n
$$

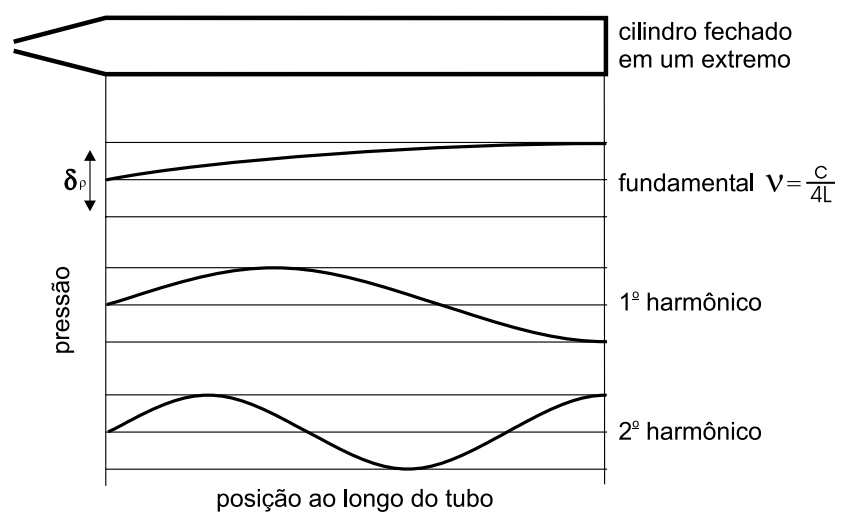

Figura 6 - Na figura temos representados os modos de vibração da pressão correspondentes aos três primeiros harmônicos para o gás no interior de um cilindro fechado em um extremo e aberto no outro.

Como $\ell<L$, i.e., como o comprimento do fio é maior que o comprimento da cabaça, e o mínimo valor de $m$ é $m=1$, então os modos tais que $n<L / \ell$ não ressoarão, ou seja, não serão amplificados pela cabaça. Concretamente, suponhamos que $L / \ell=6$, ou seja, admitamos o comprimento do fio como 6 vezes maior que o da cabaça. Isto significa que na cabaça ressoarão aqueles modos excitados no arame tais que $n \geq 6$. Mas, ainda assim, não todos os modos, e sim apenas aqueles para os quais correspondam um $m$ que seja um número inteiro (natural). Assim, para $n=6$ corresponderá a $m=1$, para $n=12$ corresponderá $m=2$, para $n=18$ teremos $m=3$ e assim sucessivamente.

Vejamos agora o que acontece quando apoiamos a cabaça na barriga. Neste caso a relação entre os comprimentos de onda dos modos de vibração do arame e da cabaça devem satisfazer à igualdade $\lambda_{n}=\lambda_{p}$, com o índice p representando o caso da cabaça apoiada. Com as Eqs. (4) e (14) obtemos

$$
\frac{2 L}{n}=\frac{4 \ell}{2 p+1} .
$$

Neste caso temos

$$
p=\frac{\ell}{L} n-\frac{1}{2} .
$$

O fato de que os modos amplificados quando a cabaça está afastada do corpo são distintos dos que quando a mesma está apoiada na barriga, se manifestam matematicamente na presença do termo $1 / 2$ na Eq. 15. Neste caso tem que ser cumprida a relação 
$p \geq 0$, o que significa que $n$ tem que satisfazer à relação $n \geq L / 2 \ell$. Se considerarmos novamente o caso em que $L / \ell=6$, então os modos do arame com $n \geq 3$ serão os amplificados, mas novamente não todos, senão apenas aqueles para os quais $p$ é um número natural. Então, para $n=3$ corresponderá a $p=0$, para $n=9$ teremos $p=1$, enquanto para $n=15$ teremos $p=2$ e assim sucessivamente.

Comparando os modos excitados quando a cabaça está afastada da barriga com os que resultam quando a cabaça está apoiada vemos que, neste último caso, serão amplificados modos mais baixos que no caso anterior. É por esta razão que ouvimos um som mais grave quando o berimbau está apoiado na barriga que quando dela está afastado.

Ao assistirmos a uma roda de capoeira, antes dela começar, é comum ver aos capoeiristas que vão tocar os instrumentos, "afinar" o berimbau. Isto é, eles batem no arame do berimbau e ouvem o som produzido, e mudam a posição da cabaça, ou seja o comprimento do arame e, secundariamente, a tensão da corda, até que o som seja do seu agrado. Assim eles buscam o comprimento da corda que possua um modo fundamental que faz ressoar a cabaça com a maior eficiência.

\section{Agradecimentos}

Os autores gostariam de expressar o seu agradecimento a Ricardo Pamfilio de Sousa, a Ângela Lünning e a Carlos Alexandre Wuensche pela indicação de algumas fontes e por conversas e críticas. Juliana Gutmann foi de grande valia na revisão final do texto.

\section{Apêndice: Nota histórica sobre a ca- poeira}

A menção da palavra berimbau pode remeter o ouvinte, ou leitor, a uma série de idéias, que podem variar segundo o seu interesse pessoal, gosto ou experiência vivida: Bahia, Salvador, música, instrumento, luta e dança. Certamente, também, remete a uma outra palavra: capoeira. Esta dança, jogo atlético, esporte, luta marcial ou como se queira classificar a capoeira, inevitavelmente é associada ao instrumento atualmente conhecido no Brasil como berimbau. Nem sempre, no entanto, foi assim. Como veremos, esta associação entre o berimbau e a capoeira ocorre numa época bem posterior ao surgimento, independente, de cada um. O instrumento, hoje popular não apenas na Bahia mas onde quer que a capoeira seja praticada, tem a ele associados que conceitos físicos? Como ele "funciona"? Como e porque ocorrem as variações de altura e os distintos efeitos fisiológicos provocados em quem o ouve?
Esperamos que o texto, ainda que minimamente, tenha respondido a estas questões.

O termo capoeira, hoje associado à luta/dança, era inicialmente designativo do praticante da mesma. Desta maneira, o capoeira, ou "mandingueiro", era o praticante da luta/dança, freqüentemente em grupos, aos quais o termo capoeiragem era associado. A própria palavra, capoeira, tem origem não muito clara. Para alguns tem raiz na língua Tupi/Guarani, onde o termo caá-puêra significaria lugar onde existiu mato virgem mas onde não há mais. Neste sentido, o nome estaria associado aos locais onde a luta/dança era praticada, locais afastados e de acesso restrito, vez que a prática da dança/luta era fortemente combatida pela classe dominante, inclusive com o emprego de forças policiais [2]. Esta característica marginal da prática da capoeira explica, inclusive, a pouca documentação existente a respeito ou, quando existente, ela contém essencialmente a visão do europeu, normalmente ressaltando apenas os aspectos negativos ou exóticos da manifestação. Há, no entanto, uma outra possibilidade para a origem da palavra, esta com raiz africana. Na região Bantu de Angola, a palavra ka/pwe/re é um verbo da língua Umbundu (Mbundu), cujo significado é "bater as mãos". Esta possibilidade, levantada por Gerhard Kubik [2], ainda que não se possa admitir como definitiva, merece ser considerada, principalmente em razão de que parece não haver dúvida sobre a origem angolana da capoeira. Ao sul de Angola, a capoeira era conhecida como n'golo, forma de luta associada ao fato de que o vencedor poderia casar sem pagamento de dote.

A capoeira não é a única forma de luta/dança com acompanhamento musical. Há referências a outras formas de luta, no Caribe e na África, que também se realizam com acompanhamento musical. O acompanhamento musical associado à capoeira não era feito como atualmente, isto é, não se realizava com o berimbau. As fontes de referência, até cerca de metade do século XIX, não apresentam capoeira e berimbau em conjunto [2] O pintor alemão, Johann Moritz Rugendas, que passou quatro anos no Brasil, tendo inclusive visitado a Bahia, faz referência aos termos "jogar capoeira", ou "jogar capoëra" e ainda à "danse de la guerre". Na sua pintura, com o nome de San Salvador (ver Fig. 7), num cenário que aparentemente era o da península de Itapagipe (região da Cidade Baixa, em Salvador), aparecem lutadores diante de uma platéia, sem a presença de instrumentos ou de gestos que pudessem sugerir palmas. Em outra ilustração, do mesmo artista, aparecem, em primeiro plano, dois negros lutando. Além disto, a ilustração mostra outros negros, um tocando tambor, outro batendo palmas e mais alguns em pé - sem nada que possa indicar a presença de um berimbau, este indispensável em qualquer roda de capoeira de hoje em dia. 


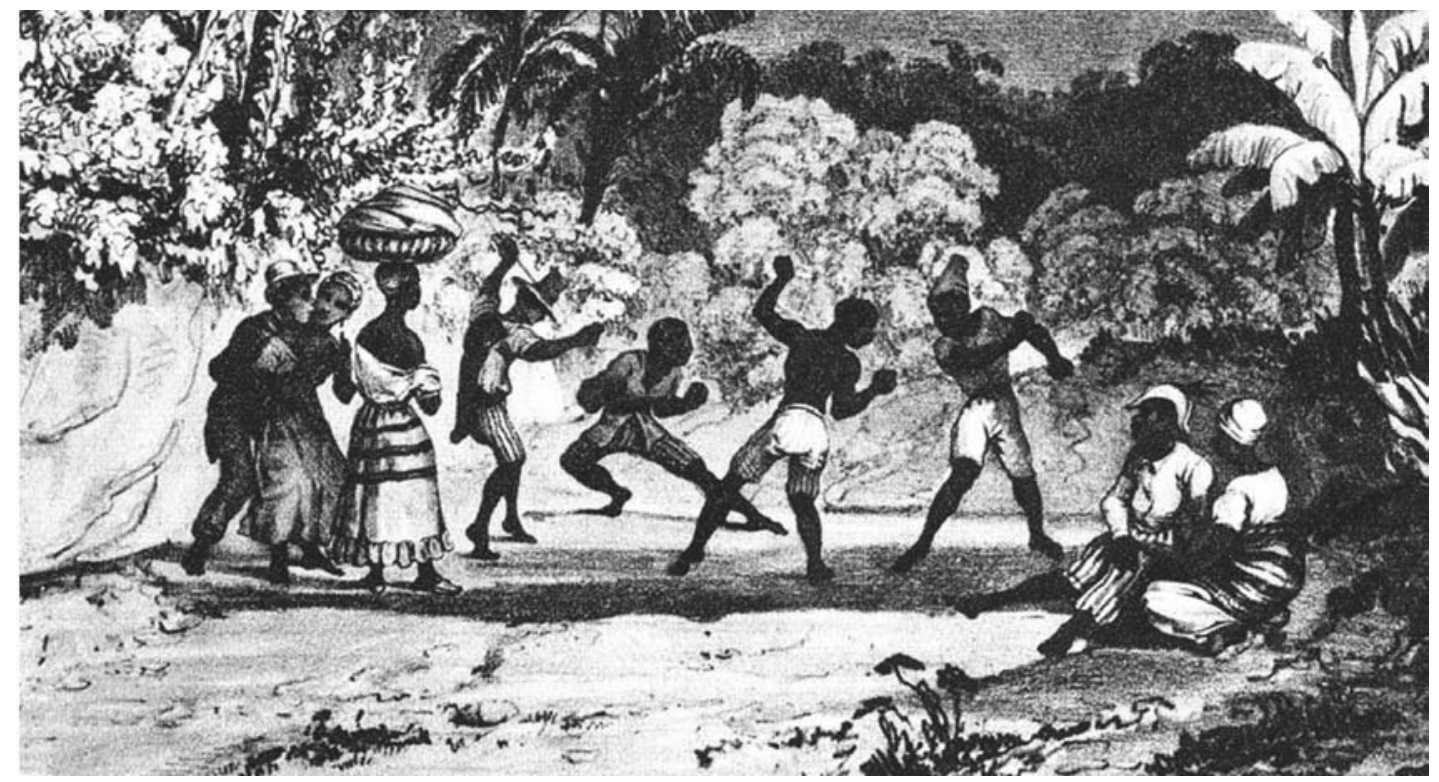

Figura 7 - Detalhe de pintura de J.M. Rugendas. As posições dos indivíduos sugerem o jogo/dança da capoeira, sem que se observe a presença do berimbau.

A capoeira, na primeira metade do século XX, passou a apresentar uma nova dimensão, tanto no aspecto da luta/dança em si, como na sua inserção social. Surge então o jogo da Capoeira Regional e o da Capoeira de Angola, com características específicas. O emprego do berimbau nas duas formas de capoeira hoje existentes, Regional e de Angola, também é distinto. Na regional temos o uso de um berimbau, enquanto na de Angola utilizam-se três, com alturas diferentes e distintas afinações.

Musicalmente o berimbau é definido como um arco musical - esta é a sua definição na Organologia. Há uma controvérsia sobre se o arco musical foi desenvolvido a partir do arco de caça ou ao contrário. No entanto, parece não haver dúvida que o arco musical estava em uso cerca de 15000 anos atrás. Não existem registros a respeito da existência de qualquer tipo de arco musical entre os indígenas do Brasil. Assim, tudo leva a crer que o instrumento chega ao Brasil por intermédio dos escravos africanos, presentes no Brasil desde a metade do século XVI.

Vários são os nomes associados ao que hoje denominamos de berimbau. Humbo, rucumbo, violâm, hungo, uricungo e lucungo. Na Bahia há referência aos termos gunga, viola e berimbau [4]. Segundo os mestres da capoeira, gunga é o nome africano, enquanto berimbau seria o nome português. Esta origem européia, segundo os registros históricos, parece decorrer de birimbao - um instrumento composto por um pequeno arco de arame e madeira com uma lâmina colocada no meio. A palavra gunga parece derivar de hungu, palavra angolana que designa chocalho. No Brasil, quando temos dois berimbaus que tocam juntos, o de som mais agudo é denominado de viola e o de som mais grave é chamado de gunga.
O berimbau, no Brasil, adquiriu várias formas. Além da forma européia, já brevemente descrita, temos, ou tivemos, vez que é difícil ou mesmo impossível encontrá-los mesmo em museus, o berimbau-de-boca e o berimbau-de-bacia. Em comum, entre estes instrumentos, há o fato de serem constituídos por uma corda vibrante e uma caixa de ressonância, esta podendo ser, conforme indicado pelos nomes dos instrumentos, a boca ou latas.

O berimbau, como o conhecemos na atualidade, é o que foi denominado de berimbau-de-barriga ou gunga - instrumento que utiliza uma cabaça como caixa de ressonâcia, possibilitando maior volume, quando comparado com o berimbau-de-boca. Historicamente o berimbau teve um papel bem distinto do atual. Foi utilizado como coadjuvante em vários papéis: para pedir esmolas, para vender produtos e, só mais recentemente, na dança/luta da capoeira.

\section{Referências}

[1] C.A. Wuensche, A Física da Música (INPE/MCT - Divisão de Astrofísica, São José dos Campos, 2004).

[2] R. Pamfilio de Sousa, A Música na Capoeira: Um Estudo de Caso. Dissertação de Mestrado, Universidade Federal da Bahia, 1997.

[3] F. Miyara, La música de las Esferas: de Pitágoras a Xenakis... y más acá. Apuntes para os seminários do Departamento de Matemática da Faculdade de Ciências Exatas, Ingeniería e Agrimensura da Universidade Nacional de Rosario, Argentina, 2005.

[4] K. Shaffer, O Berimbau-de-Barriga e Seus Toques. Monografias Folclóricas 2, Ministério da Educação e Cultura, Funarte, 1977. 